\title{
Música, cultura e experiência
}

\author{
JoHN BLACKING \\ Traduçấo: André-Kees de Moraes Schouten \\ Revisáo técnica: Daniela do Amaral Alfonsi, Paula Wolthers de Lorena Pires e \\ Thaís Chang Waldman
}

A "música" é um sistema modelar primário do pensamento humano e uma parte da infraestrutura da vida humana. O fazer "musical" é um tipo especial de ação social que pode ter importantes conseqüências para outros tipos de ação social. A música não é apenas reflexiva, mas também gerativa, tanto como sistema cultural quanto como capacidade humana. Uma importante tarefa da musicologia é descobrir como as pessoas produzem sentido da "música", numa variedade de situações sociais e em diferentes contextos culturais, distinguindo entre as capacidades humanas inatas utilizadas pelos indivíduos nesse processo e as convençôes sociais que guiam suas açóes.

Essa tarefa começa a ser revolucionada pela invenção do fonógrafo e do gravador, e segue com a descoberta e a análise de sistemas musicais de diferentes partes do mundo, muitos dos quais estão baseados em princípios de organizaçáo tonal que podem ser extremamente mal interpretados quando analisados com os parâmetros derivados da experiência da tradição da música "artística" européia. Isto foi reconhecido, em 1885, pelo físico e foneticista britânico Alexander John Ellis que, após mensurar as escalas musicais de sociedades diferentes, concluiu:

A escala musical não é única, natural, nem fundada necessariamente sobre as leis da constituição do som musical, como táo bem formulado por Helmholtz, mas muito diversa, muito artificial e muito caprichosa (Ellis, 1885, p. 526).

O fonógrafo e o gravador ajudaram a tornar as pessoas mais conscientes sobre a criatividade geral humana em relação à invenção, à performance e à apreciação da "música". Estes equipamentos aboliram o que era visto como diferenças essenciais entre "músicas" escritas e não-escritas, e entre músicas "artística", "popular" e "folclórica”. As análises das gravaçôes das músicas nãoescritas revelaram que as "folclóricas" e algumas tradiçôes da música "artística" asiática são menos improvisadas, mais estáveis e sistemáticas do que geralmente se pensava. As interpretaçóes gravadas da música escrita mostraram que, mesmo para o mais erudito e cuidadoso dos performers, a partitura é apenas um guia aproximado para a performance. Assim como as múltiplas gravaçóes de uma sinfonia de Beethoven mostram que há tantas leituras quantas são as orquestras e os regentes, também as gravações da improvisação aparentemente "espontânea" da música africana revelam uma coerência da performance, sugerindo que os músicos retêm em suas cabeças tanto a gramática de um sistema musical como o equivalente de uma partitura.

O incremento nas gravaçôes das músicas do mundo nem sempre conduziu ao esclarecimento musical, uma vez que as pessoas tendem a procurar significados familiares no não-familiar, como se os homófonos see, see, sea e si tivessem o mesmo significado. Também é moda entre os compositores selecionar e utilizar as sonoridades exóticas que os atrai, tal como os colonialistas produziram bens manufaturados a partir de matérias-primas dos países do terceiro mundo. Se os compositores e etnomusicólogos encarassem o problema de aprender um novo sistema musical por meio do trabalho com os músicos e do estudo com professores, como 
fariam num conservatório europeu ou norteamericano, seriam recompensados pela descoberta de processos inesperados que entram na produção da música, e sua compreensão da "música" como uma capacidade humana poderia ser ampliada, bem como sua experiência musical seria enriquecida.

Um bom exemplo de um processo musical inesperado foi proporcionado pelas segundas maior e menor das duas partes da ganga da Bósnia-Herzegovina (ver Petrovic, 1977) e pelo Schwebungsdiaphonie (ver Messner, 1980), encontrado nas mais diferentes sociedades européias, asiáticas e oceânicas. O que alguns ouvidos escutam como tensôes dissonantes, para os cantores são profundamente concordantes e uma fonte de experiência transcendental.

Mesmo que todas as sociedades humanas conhecidas possuam aquilo que musicólogos treinados reconhecem como sendo música, em algumas não há uma palavra para música ou existe um conceito de música cujo significado é bem diferente daquele geralmente associado à palavra "música". Todavia, "música" é uma palavra oportuna que tem uma função analítica similar ao conceito de "tipos ideais" formulado por Max Weber. Assim entendida, "música" pode encerrar tanto a enorme gama de "músicas" que os membros de diferentes sociedades categorizam como sistemas simbólicos especiais e tipos de ação social, como um quadro inato específico de capacidades cognitivas e sensoriais que os seres humanos estáo predispostos a usar na comunicação e na produção de sentido do seu ambiente. A "música" é tanto um produto observável da ação humana intencional como um modo básico de pensamento pelo qual toda açáo pode ser constituída. A expressáo mais característica e efetiva deste modo de pensamento é o que poderíamos chamar "música", mas isto também pode se manifestar em outras atividades, até na organização de idéias verbais, tal como o famoso discurso de Martin Luther
King, "Eu tenho um sonho", ou algumas das poesias de Gertrude Stein.

As fontes de informação mais acessíveis sobre a natureza da "música" são encontradas, em primeiro lugar, na variedade de sistemas, estilos ou gêneros musicais que são atualmente realizados no mundo. Segundo, nas gravaçóes históricas de partituras escritas, na iconografia e nas descrições de performances. E, em terceiro lugar, nas diferentes percepções que as pessoas têm da música e da experiência musical, por exemplo, nas diferentes maneiras pelas quais as pessoas produzem sentido dos símbolos "musicais". Embora apresente um problema filosófico, esta terceira fonte é para os antropólogos a mais importante, porque reconhece que as "músicas" são fatos sociais e que a análise das composições e das performances musicais deve, portanto, levar em conta tanto o trabalho dos críticos e "leitores de textos" como dos performers e recriadores da "música". O "objeto artístico" em si não é arte nem não-arte: torna-se um ou outro somente pelas atitudes e sentimentos que os seres humanos lhe dirigem. A arte vive em homens e mulheres, sendo trazida a público por processos especiais de interação. Desta maneira, os signos náo possuem significados até que estes sejam compartilhados, e assim tais processos tornam-se cruciais para a semiótica da música, como o produto sônico que fornece o foco para a análise (Blacking, 1981, p. 192). Clifford Geertz ilustrou este ponto mais sucintamente com a seguinte frase reveladora: "A arte e o equipamento para sua compreensão são produzidos na mesma oficina” (Geertz, 1976, p. 1497).

Para compreender a "música" como uma capacidade humana, como um quadro específico das capacidades cognitivas e sensoriais, devemos começar tratando sua definição como problemática, e é por isso que coloquei o conceito entre aspas. Além de incorporar numa teoria geral da "música" as características de todos 
os diferentes sistemas musicais, ou "músicas", devemos também levar em conta as diferentes maneiras pelas quais os indivíduos e os grupos sociais produzem sentido daquilo que eles ou qualquer outro considera como "música".

Desta maneira, quando um estudante universitário queniano produziu uma análise "errada”, não-toveyniana, do primeiro movimento da Sonata para Piano de Beethoven op. 49, no.

2, foi necessário descobrir porque sua versão entrava em conflito com as de seus colegas de classe que foram bem-sucedidos ao produzirem uma versão "correta". Como examinador externo discordei das notas baixas dos examinadores internos, porque o estudante havia produzido uma análise perfeitamente lógica, embora desviante, na qual enfatizava o contraste de períodos, padróes rítmicos e a textura de baixo e agudo, ao invés das tonalidades e dos motivos melódicos. Freqüentemente são estas análises "desviantes" das partituras musicais que produzem altas somas de dinheiro para regentes, instrumentistas e companhias de discos e, no entanto, este fato da vida musical nem sempre é reconhecido pelos musicólogos e teóricos da música, que às vezes assumem ser sua tarefa a produção de análises definitivas da obra-prima musical, dos estilos e dos períodos da história da música. Como música e experiência musical humana, a sonata Hammerklavier de Beethoven se estende muito além da partitura escrita, de um momento particular da história ou de qualquer performance singular.

Diferentes remontagens e diferentes percepçôes da sonata tornam-se parte dela, exatamente como a criaçáo original e a primeira performance dependem da tradição pianística (Blacking, 1981, p. 190).

Somente quando os musicólogos se aperceberem das leituras alternativas dos textos sagrados teráo o direito, como seres que fazem "música", de discordar das classificações indígenas. Por exemplo, os muçulmanos não classificam o canto Quranic como música, mas ele possui características em comum com o canto gregoriano e com outros tipos de cantos que muitos musicólogos consideram como tal, podendo assim ser incluído na evidência contra a qual a teoria geral da música deve ser testada.

De qualquer modo, todo discurso sobre a "música" apresenta um problema filosófico porque pertence a uma esfera discursiva diferente daquela do sujeito da investigação: a música. $\mathrm{O}$ discurso musical é essencialmente não-verbal, embora obviamente as palavras influenciem suas estruturas em vários casos, e, ao analisar linguagens não-verbais através da linguagem verbal, corre-se o risco de distorcer a evidência. Portanto a "música" é, estritamente falando, uma verdade indecifrável e o discurso sobre ela pertence ao domínio da metafísica. Todavia, não precisamos nos preocupar demais por usar uma linguagem para descrever outra e tampouco precisamos nos desesperar em verificar verdades musicais, contanto que reconheçamos ser a linguagem verbal aproximativa e a objetividade impossível, pois construída subjetivamente no interior do modelo de investigação. Ou seja, já que essa verdade indecifrável só pode ser abordada de maneira indireta ou oblíqua, o conteúdo verbal subjetivo levado em conta pelos indivíduos possui um status especial como dado na procura por continuidades e descontinuidades, homologias e contradiçôes nas maneiras pelas quais as pessoas falam sobre o que acreditam ser "música".

\section{"Música” como sistema cultural}

O conceito antropológico de cultura difundiu-se (ver Schneider e Bonjean, 1973) e substituiu o uso comum da palavra, porém mais restrito, para o qual "cultura" se refere às 
"artes" e às atividades "refinadas". A definição proposta por Tylor era mais abrangente:

Cultura [...] é o todo complexo que inclui conhecimento, crença, arte, moral, lei, costume e tantas outras capacidades e hábitos adquiridos pelo homem enquanto membro da sociedade (Tylor, 1871, p. 1).

O conceito de cultura é uma abstração esboçada para descrever todos os padróes de pensamento e interação, "um sistema organizado de símbolos significantes" (Geertz, 1975, 46), que persiste nas comunidades ao longo do tempo. Os instrumentos musicais e as transcriçôes ou partituras da música neles tocada não são a cultura de seus criadores, mas as manifestaçôes desta cultura, os produtos de processos sociais e culturais, o resultado material das "capacidades e hábitos adquiridos pelo homem enquanto membro da sociedade". Não podemos "ver" uma cultura: somente podemos inferí-la das regularidades na forma e na distribuição das coisas que observamos.

Toda performance musical é, num sistema de interação social, um evento padronizado cujo significado náo pode ser entendido ou analisado isoladamente dos outros eventos no sistema. Como Geertz observou,

O problema capital apresentado pelo fenômeno completo do poder estético, qualquer que seja a forma e o resultado da habilidade que o gerou, é como colocá-lo entre outros modos de atividade social, como incorporá-lo na textura de um padrão de vida particular (1976, p. 1475).

Ele ressalta ainda que "um artista trabalha com signos que possuem um lugar no sistema semiótico, estendendo-se para além do ofício que ele pratica" (1976, p. 1488). Geertz cita o Painting and experience in fifteenth-century Italy de Michael Baxandall, enfatizando que diferentes domínios da cultura renascentista contribuíram nos modos pelos quais os italianos do século XV olhavam para as pinturas: "Piero della Francesca se inclina para um tipo de pintura relacionada com a avaliação, Fra Angelico com a pregação religiosa e Botticelli com a dança”" (Baxandall, 1972, p. 152).

Isto não significa que toda a atividade musical possa ou deva ser reduzida a uma variedade de atividade social e interpretada de maneira intercambiável com qualquer outro conjunto de instituições. No fundo, a música é o aspecto mais importante do fazer musical, não somente para quem a estuda, mas também para aqueles que participam dela. Este é o caráter especial das atividades musicais que é sociológica e antropologicamente problemático, mais que as características que elas têm em comum com outras atividades sociais. O problema é descobrir como as pessoas integram e utilizam diferentes tipos de experiência, especialmente a experiência musical, e como elas relacionam música à não-música e um tipo de música a outro.

Quando ouvi pela primeira vez, em 1956, algumas canções de criança dos venda da África do Sul, por exemplo, não compreendia como eles podiam preparar as crianças para a música dos adultos, que já ouvira em muitas ocasióes. E a meu ver, no entanto, deveriam existir relaçôes estruturais entre as duas. Assumindo que as canções de criança são os primeiros passos na obtenção das habilidades musicais venda, procurei analisá-las em termos de teorias "universais" de intervalos, tonalidades e estruturas musicais elementares. As primeiras tentativas de análise musical formal foram mal-sucedidas, na medida em que falharam em revelar a coerência das cançóes de criança tanto como um gênero quanto em relação a outra música venda, além de faltar a precisão e a parcimônia que se esperaria de uma análise convincente. Finalmente, discussóes com os músicos e um 
longo contato com sua sociedade e sua cultura me levaram a uma análise cultural do contexto sensitivo das músicas de criança (Blacking, 1967) que mostrou as relaçóes entre estruturas musicais e padrôes da vida social e cultural.

Dessa maneira, embora a comparação intercultural seja uma tarefa na análise das diferentes músicas e um passo em direção ao entendimento da "música" como uma capacidade humana, um sistema musical deveria, em primeiro lugar, ser analisado não em comparação com outras músicas, mas em relação a outros sistemas sociais e simbólicos dentro de uma mesma sociedade. Tanto na teoria quanto no método há uma diferença significativa entre o estudo intensivo de outras músicas como sistemas culturais coerentes e o estudo comparativo de outras músicas-em-performance. Tradicionalmente, procurava-se compreender os sistemas musicais nos termos dos diferentes tipos de percepçóes que seus compositores, performers e espectadores habituais fazem deles - embora os últimos estejam inevitavelmente produzindo sentido das músicas dentro dos parâmetros derivados do sistema musical do próprio analista - ou de alguma hipotética teoria universal do fazer musical humano. Para entender tanto uma tradição musical quanto as contribuições que compositores individuais dão a ela, um sistema musical deve ser compreendido como um dos diferentes quadros de símbolos pelos quais as pessoas aprendem a produzir um sentido público de seus sentimentos e da vida social.

Uma vez que tanto os ouvintes como os compositores e performers são parte do processo do fazer musical, e desde que haja evidência de que todo ser humano tem a capacidade de produzir sentido da música (cf. Blacking, 1973), a visão que um músico tem da música é uma fonte limitada de informação, até mesmo sobre os aspectos estritamente musicais de um sistema musical. De fato, já que sua arte exige grande dedicação a uma prática socialmente isolada, às vezes os músicos podem ser menos perceptivos que os ouvintes sobre os importantes significados de sua arte, e eles raramente são mais articulados que a média do leigo sobre os processos de endoculturação dados por certos na performance. A performance de músicos e compositores, as gravaçôes e partituras musicais são importantes fontes de informação sobre as práticas musicais de uma sociedade e de seus componentes, mas não são de maneira alguma as únicas fontes primárias. $\mathrm{E}$ até que a importância das visóes "leigas" na compreensão e na análise das músicas seja reconhecida, não progrediremos em direção à compreensão da "música" como uma capacidade humana.

Como isto pode ser feito? Nem o fonógrafo ou a fita cassete, nem mesmo o melógrafo, o sonograma ou outros dispositivos eletrônicos proporcionariam as chaves mais significativas para a compreensão da natureza do discurso "musical", ainda que ofereçam meios para a escuta repetida e para a observação cuidadosa do fenômeno acústico, podendo sensibilizar as pessoas para a complexidade e a variedade das músicas não-familiares. Como ferramentas de pesquisa, podem ser usados para testar, confirmar ou refutar aquilo que as pessoas intentam ou acreditam ser música. Mas aquilo que podem reproduzir incansavelmente e dissecar meticulosamente proporciona apenas uma ilusão de objetividade, porque a essência do fazer e da compreensão musical são os atos humanos de produzir sentido com os símbolos musicais através da composição, da performance e da audição. Os "fatos objetivos" das estruturas musicais podem aparentemente estar ali para todos ouvirem ou verem, mas na verdade não estão. O significado dos signos musicais é ambíguo, mais culturalmente limitado que objetivamente auto-evidente. As pessoas estão propensas a percebê-los e interpretá-los com referência às suas experiências de diferentes sistemas culturais, assim como conforme as variaçôes na 
personalidade individual. As interpretaçôes ambíguas dos signos musicais são provavelmente as mais poderosas fontes de inovação e transformação musical, isto é, quando certas circunstâncias sociais estimulam o desenvolvimento de uma maneira idiossincrática de ouvir música, em vez daquela aprovada culturalmente, é mais provável que se componham músicas abertas a novas direçôes.

Dessa maneira, como sugeriu Charles Seeger (1977), as variedades de discurso sobre a música são provavelmente as mais confiáveis fontes de informaçáo sobre os diferentes tipos de discurso musical. As maneiras pelas quais as pessoas "situam" a música "dentro de outros modos de atividade social"; as classificaçôes, metáforas, similaridades, metonímias, analogias e outros meios que utilizam para incorporá-la na textura de seu "padrão de vida particular"; e as decisóes que tomam pela - ou por causa da - performance musical são pistas vitais na descoberta de gramáticas musicais e de tipos de pensamento e inteligência envolvidos no fazer das músicas do mundo.

A grande contribuição da etnomusicologia para o conhecimento musical é a expansão do saber acerca das possíveis conceitualizaçóes das músicas e da performance musical. Estas são mais importantes que a descoberta de novas estruturas musicais, porque sugerem maneiras alternativas de ouvir tanto as novas músicas como as músicas já familiares. Elas desafiam as bases da maioria das análises psicológicas, sociológicas e musicológicas da música e da musicalidade, especialmente aquelas que reivindicam ser mais científicas que humanísticas porque rompem as divisóes convencionais entre o jargão das descrições "leigas" e "técnicas" das formas musicais. Elas revelam não apenas uma enorme variedade de musicalidades na sociedade humana do que geralmente acreditávamos existir, mas também novas e coerentes idéias sobre a organizaçáo do som que nem sempre podem ser acomodadas dentro dos parâmetros das análises musicais "científicas" derivadas da experiência de uma tradição musical particular, a música tonal européia.

A música tonal européia também foi matéria de diferentes tipos de discurso e estilos de interpretação, e o processo de compô-la, interpretá-la e experimentá-la foi por longo tempo descrito e avaliado com uma terminologia não-musical. Mas este modo de discurso sobre a música é geralmente considerado como auxiliar ou referencial, ainda que essencial na compreensão das estruturas musicais para as quais os diferentes modos de discurso quase científicos foram desenvolvidos. Gostaria de sustentar que o jargão técnico da descrição musical não é substancialmente diferente e não deveria ser separado do discurso "não-técnico", exceto quando são linguagens de grupos sociais particulares. $\mathrm{O}$ uso, ou não, dos termos técnicos na descrição musical é tâo arbitrário quanto o fato de que a maioria das pessoas fala de diarréia e bronquite, mas somente os médicos e as enfermeiras falam de dispepsia, embora isto seja uma experiência humana igualmente comum. Quando um amigo ou parente está severamente doente, aprendemos logo o jargão e descobrimos que os médicos raramente compreendem o processo da doença melhor do que as pessoas leigas, os que padecem dela ou que estão próximos a ela.

E assim é com a música. Embora o discurso musical, ou a "forma em movimento tonal", seja o objeto da criação, da percepção e a fonte da experiência musical, termos técnicos como "melodia", "tonalidade", "intervalos", "harmonia", "quartas", "quintas", "terças" etc., precisam ser generalizados para que possam descrever a organização cognitiva de outros fenômenos, símbolos e conceitos, assim como os sons da música (cf. Blacking, 1984). A música é freqüentemente gerada por regras não-musicais. A metalinguagem comumente usada nas 
análises musicais pode de fato impedir o desenvolvimento de gramáticas musicais, porque é culturalmente específica e irrelevante para compreender muitas das músicas do mundo.

Embora os termos técnicos das análises musicais tenham algum valor heurístico como palavras "luminosas" para se referir a formas que são externamente similares, eles não são adequados para descobrir os significados "intrínsecos" aos diferentes períodos e aos gêneros da música européia, deixando de lado as músicas asiática e africana. A precisão com a qual as pessoas podem descrever, avaliar e relacionar a música com outras atividades humanas (ver, por exemplo, Feld, 1982, sobre a música dos Kaluli de Papua Nova Guiné) sugere que a música tonal européia poderia ser facilmente descrita em geral, com termos não-musicais, de tal maneira que suas estruturas e significados possam ser mais facilmente correlacionados com outras características das culturas européias e até mesmo com as músicas não-européias.

Para concluir esta seção, as implicaçôes de tomar as músicas como sistemas culturais podem ser declaradas resumidamente. Partituras musicais são prescritivas e apenas representaçóes aproximadas dos sons pretendidos de uma peça musical. Transcriçóes descritivas de performances gravadas podem ser mais precisas. Mas como dois performers pensam sobre a mesma passagem pode fazer uma grande diferença para suas performances, mesmo que aparentemente não haja diferenças observáveis em seus movimentos de dedo, punho e braço. Como os ouvintes pensam sobre essas mesmas performances pode ser um fator adicional na comunicação e na interpretação. Dessa maneira, como as pessoas pensam sobre o que elas consideram como performance musical é a chave para compreender a estrutura e o significado dos símbolos musicais.

Uma teoria útil surgirá não tanto do teste de hipóteses constituídas dentro de um sistema musical particular, mas da conjunção dinâmica de sistemas e disciplinas alternativas. Isto não é como um diálogo entre pessoas no qual um deve dominar ou ambos devem tomar parte sem afetarem um ao outro, mas sim uma fusão onde as duas partes saem transformadas e renovadas, uma viagem de descoberta mútua na qual diferentes maneiras de pensar sobre a música ganham um status heurístico igual, num terreno onde todos os seres humanos são capazes de produzir sentido da música.

\section{Pensar e falar sobre música: uma abordagem dialética}

Situei o problema da cognição musical como central na compreensão e na análise de diferentes músicas, e evitei deliberadamente as falsas dicotomias como pensamento/sentimento, razão/emoção e mente/corpo, que freqüentemente atrapalham as discussões sobre os símbolos e a experiência musical (cf. Blacking, 1977). Todavia, gostaria de distinguir dois modos de discurso contrastantes mas complementares, que são componentes necessários do fazer musical e que também podem revelar como as pessoas pensam sobre a música:

Verbal: falando sobre música como analistas e usuários da música. (A categoria de "analista" inclui as pessoas que interpretam, escutam e avaliam a música, assim como os pesquisadores e acadêmicos).

Não-verbal: a interpretação como uma maneira de cumplicidade, especialmente a experiência bi-musical, isto é, aprendendo a interpretar adequadamente a música de duas tradiçôes diferentes. (Isto inclui as performances normais e as performances organizadas como testes do pensamento musical das pessoas [como em Blacking (1959) e Arom (1976)]. Além disso, como argumentei anteriormente, 
ouvir música é um tipo de performance, na medida em que os ouvintes devem ativamente recriar e produzir sentido com os sons que ouvem.)

A mais completa compreensão da música e o enriquecimento pela experiência musical vêm da combinação desses dois modos de discurso. Assim, as análises do pensamento musical devem incluir os dois tipos de informaçáo, mas sempre no contexto de seus usos sociais e no sistema cultural do qual fazem parte. Para enfatizar a dinâmica e os papéis não-reflexivos que os músicos podem desempenhar na vida social e na organização cultural, e focar na significância dos símbolos musicais, prefiro não pensar em termos de uma sociomusicologia, que identifica a criação e a interaçáo musical sobretudo como uma parte auxiliar da vida social, mas de uma musicossociologia, que poderia ver certos aspectos da vida social como produtos do pensamento "musical". Isto é mais interessante para desafiar o modelo da superestrutura artística de base econômica da sociedade em geral, não porque eu rejeite este modelo, mas porque não me parece ser universalmente válido. O que pode explicar de maneira magnífica o modo de produção capitalista e o crescimento do imperialismo na Europa e na América do Norte num tempo particular da história humana, e o que pode explicar os padróes das civilizaçôes hidráulicas e os modos de produção feudais na Ásia, não explica necessariamente todas as formaçôes sociais em todos os períodos da história humana.

A idéia de que a cognição artística é uma importante fonte da vida humana, e de que a práxis artística pode influenciar e iniciar a ação social, não deveria ser dispensada como uma reatualização da visão romântica das artes do século XIX. Não estou afirmando que as músicas ou as artes em geral são o motor da mudança, ou que tenham uma função de solucionar problemas. Estou preocupado com as funçôes cognitivas da música e, na seção final deste trabalho, sugiro que o fazer musical pode ser uma ferramenta indispensável para a intensificação e a transformação da consciência como um primeiro passo para transformar as formas sociais. Em "The music of politics" (Blacking, 1995b) ofereci um exemplo da África do Sul, onde a prática musical foi um importante elemento no desenvolvimento da consciência política e da ação efetiva. Ben Sidran (1971) descreveu a black music nos Estados Unidos como uma espécie de ação mais que de reflexão, um dos meios pelos quais a estrutura social é criada.

Esse tipo de evidência e o argumento sobre a "música" como um sistema modelar primário apontam para uma estratégia de pesquisa que toma os "grupos sonoros" como unidade básica de análise, mais que compositores individuais, grupos sociais, comunidades ou culturas per se. Um "grupo sonoro" é um grupo de pessoas que compartilha uma linguagem musical comum, junto com idéias comuns sobre a música e seus usos. A pertença aos grupos sonoros pode coincidir com a distribuição das linguagens verbais e das culturas, ou pode transcendê-las, como em partes da Europa e nas Terras Altas de Papua Nova Guiné. Numa mesma sociedade, as diferentes classes sociais podem ser distinguidas como grupos sonoros distintos, ou podem pertencer ao mesmo grupo sonoro, embora estejam profundamente divididas em outras circunstâncias.

Se olharmos para a prática "musical" como uma força ativa na formação das idéias e da vida social, como comunicação náo-verbal que é a base mas também transcende categorias e grupos sociais definidos e sustentados com palavras, devemos procurar a evidência que mostre como o uso dos símbolos musicais ajuda a fazer, assim como refletir padrôes da sociedade e da cultura. Devemos descobrir precisamente como as pessoas são capazes de relacionar as experiências com os símbolos musicais e com 
outras formas de atividade social e intelectual, e explicar isto como mais do que reações aprendidas. Este nível de explicação deve ir além dos tipos de argumento ou de suposiçấo que afirmam ser tal ou qual padrão de som destinado para - ou associado com - uma atividade ou convenção social particular, devendo, portanto, procurar seus significados essenciais nos significados desta atividade social. As sentenças abertas neste trabalho suscitaram uma questão que com muita freqüência é tomada por certa, mas que está no cerne de todas as discussóes acerca da comunicação musical: a possibilidade de que os símbolos musicais possam ser transformados em outros símbolos, e vice-versa, sem a mediação da convenção social.

Em minhas discussões anteriores sobre comunicação musical, em "Expressing music experience through music" (1995a) e How musical is man? (1973), deixei de tratar essa questão como problemática. Em primeiro lugar, embora questionasse algumas das conclusóes do brilhante estudo de Derryck Cooke, The language of music (1959), caí na mesma armadilha que sustenta ser os significados primários dos símbolos musicais selecionados pela convenção social. Em segundo lugar, não perguntei como as pessoas relacionariam os símbolos musicais não-verbais a outros conjuntos de símbolos sem terem uma série de equações arbitrárias, tais como: sendo $x$ (náo-verbal) $=y$ (verbal); sendo $p q$ (não-verbal $)=r($ verbal $)$ e assim por diante. Em outras palavras, as pessoas poderiam realizar conexóes entre experiências musicais e não-musicais sem regras culturais específicas? Agora estou convencido que sim, principalmente porque muitas regras culturais são feitas com os mesmos modos de pensamento que a música, e porque a capacidade do cérebro humano em relacionar diferentes transformaçôes da mesma figura náo depende completamente da experiência cultural, embora certos marcos históricos do desenvolvimento cognitivo preci- sem da prática cultural para sua plena realização (cf. Lenneberg, 1967).

Para se chegar a alguma idéia sobre as capacidades necessárias aos seres humanos na realização destas operaçôes mentais (ponto que será mais discutido na próxima seção), precisamos enfocar os problemas específicos relacionados com o equilíbrio entre a potencial capacidade musical e a prática cultural, mas sempre nos termos e no contexto de sistemas musicais diferentes. Por exemplo, sistemas musicais diferentes requerem fundamentalmente distintas capacidades, habilidades ou aptidóes? $\mathrm{Ou}$ apenas enfatizam aspectos de um repertório comum de capacidades cognitivas "musicais" e/ou gerais? Certos tipos de música são inerentemente mais difíceis de se conhecer a fundo que outros? Ou podem, em teoria, ser tão facilmente aprendidos pelos nativos "falantes" como suas linguagens verbais?

Algumas respostas a estas questôes emergirão quando soubermos melhor como as pessoas pensam sobre diferentes conjuntos de símbolos musicais e os relacionam a outros símbolos. A análise do significado só pode ser alcançada por uma dialética entre "informantes" e "analistas", na qual há uma confrontaçáo de dois tipos de conhecimento técnico e de experiência, e os "informantes" tomam parte no processo intelectual da análise. Tanto quanto for possível, isto deve ser feito em campo, sendo o processo bastante diferente daquele usualmente associado com "entrevistas". O ponto essencial é que não deve haver duas fases separadas, da coleta de dados e da análise de "laboratório". A participação, a coleta de dados, a discussão e a análise primária devem todas estar fundidas num processo analítico em andamento. Deste modo, a maior tarefa da análise é transferida para o campo, onde os experimentos ad hoc (cf. Blacking, 1959) podem ser combinados com o diálogo, bem como para testar cada conclusão. 
O segundo estágio da análise é relacionar dialeticamente as idéias e as atividades dos grupos sonoros com aquelas de outros grupos sociais e, em particular, situar o ciclo de desenvolvimento dos indivíduos dentro dessas estruturas. Como a aquisição das habilidades musicais e as correspondentes experiências corporais relacionam-se a outras atividades e experiências sociais? As experiências musicais auxiliam ou entram em conflito com outras atividades sociais? Em que medida a música é capaz de - ou intenciona - ampliar a consciência? E como as pessoas fazem as conexóes entre a música e outras experiências? (cf. Geertz, 1976, p. 1475, citado anteriormente). Geertz é um dos vários autores que busca situar a prática artística num contexto social. Ao mesmo tempo em que concordo com isto, também inverto o processo e digo que, para um etnomusicólogo, o procedimento analítico crucial não é tanto ajustar a música dentro de um sistema social, mas iniciar com um sistema musical e seus símbolos, com estilos e grupos sonoros, e entáo ver como e onde a sociedade se ajusta no interior da música. Devemos considerar a cognição artística e particularmente a prática musical como tendo papéis primários na imaginação de realidades sociais.

Supondo que haja uma unidade dos sentidos (ver von Hornbostel, 1927) e que as freqüentes integraçôes de diferentes formas de arte (ver Nzewi, 1977; Tax, 1972, 26 f.) sejam resultados de um denominador comum de cognição "artística", diríamos que as idéias e as atividades dos grupos sonoros deveriam também ser contrastadas com aquelas dos grupos "artísticos" alternativos ou complementares, assim como com os grupos "não-artísticos" em geral.

Por que os garotos dayak se expressam através da escultura (Leach, 1954) e as garotas venda através do canto e da percussão? E os garotos dayak e as garotas venda seriam carentes, emocional e intelectualmente, pela falta da percussão e da escultura respectivamente? Se uma atividade artística não é essencialmente a mesma que outra, que podemos fazer sem uma delas? Entre os venda as habilidades na música e na dança seriam tâo inextricavelmente ligadas que, por exemplo, se um homem venda disser "Eu posso tocar tshikona", quer dizer que também pode dançá-la, e se uma garota disser "Eu danço tshigombela", ela também pode cantar e tocar os tambores (Blacking, 1982, p. 34).

Algumas atividades artísticas são intrinsecamente de grande valor para o desenvolvimento de determinados indivíduos, se não das pessoas em geral, por causa das maneiras particulares nas quais exercitam o corpo? Ou a significância afetiva e cognitiva varia por causa de suas diferentes aplicações culturais? Howard Gardner argumentou que a

capacidade musical é freqüentemente encontrada entre crianças que não são excepcionais, podendo até mesmo ser deficientes em outras áreas (1973, p. 188).

Por outro lado, num estudo longitudinal entre crianças húngaras, Barkóczi e Pléh (1982) apontaram para os efeitos positivos do fazer musical nos resultados educacionais. Mostraram que embora a educação musical intensiva pelo método Kodály não tenha afetado o nível geral de inteligência das crianças, houve um efeito positivo sobre a criatividade, produzindo "uma relação mais harmônica entre criatividade e inteligência, pensamento divergente e convergente" (Barkóczi e Pléh, 1982, p. 31). Gardner também sugeriu que

provavelmente nenhuma outra pessoa viva_tocava com o virtuosismo do garoto Mozart... mas aos dezesseis anos Picasso não desenhava tão bem quanto Degas (1973, p. 198). 
As diferenças entre a aquisição da música e da pintura "refletem a natureza preeminentemente formal do meio e o fato de a música ser mais auto-contida" (ibid.) e menos dependente da experiência? Ou são estas diferenças uma conseqüência das relaçóes desses sistemas de símbolos com outros na cultura européia?

Esta questáo nos leva de volta ao tema-chave da "música" como uma capacidade humana, que é o tópico da próxima e última seção deste trabalho. Mas antes de discutir aquele tema, gostaria de resumir algumas das áreas nas quais uma abordagem dialética para a análise do fazer musical prático, em diferentes sociedades e contextos, pode nos levar a uma compreensáo mais profunda das capacidades "musicais" humanas e de suas expressões em diferentes músicas. Uma abordagem dialética pode ser aplicada como a seguir:

1. Entre analistas, por exemplo, entre Steve Feld e seus analistas Kaluli, quem (como com Stravinsky e Robert Craft) provavelmente não haviam pensado sobre muitas das coisas que Feld lhes falava até que eles tivessem o desafio intelectual advindo da visita do etnomusicólogo. Da mesma maneira, até que fosse desafiado intelectualmente pelas pessoas em Venda (incluindo as crianças), havia muitos aspectos da compreensão e da interpretação de "minha própria” música que me escapavam.

2. Entre grupos sonoros e outros grupos sociais, por exemplo, entre música e outras artes, e entre as atividades musicais e outras atividades num sistema social.

3. Entre sistemas musicais e suas lógicas contrastantes (verbal e não-verbal). Sistemas musicais são derivados de e/ou ligados a idéias e princípios de ordem utilizados numa variedade de instituições. Qual é o status do "pensamento musical"? Ele é um tipo especial de cognição humana, podendo também ser aplicado em campos não-musicais? Ou a música é a aplicaçấo de outros tipos de pensamento e de movimento corporal para a organização de tons?

4. Entre performers, performances e experiências musicais contrastantes (não-verbal). Como a experiência de um sistema musical influencia a percepção de um e a performance do outro?

5. Entre grupos sociais e estilos contrastantes, por exemplo, a confrontação nos Festivais de Folclore na situação de, digamos, Zâmbia, onde os membros da companhia nacional de dança são atraídos de todas as partes do país e ensinam uns aos outros a executar as danças comuns às diferentes regiōes. Confrontaçóes nos Festivais de Folclore muitas vezes parecem com o que George Steiner, em After Babel: Aspects of language and translation (1975), escreveu sobre a comunicação em comunidades divididas social e economicamente: "As funções agonísticas da fala... têm mais valor do que as funçôes da comunicação genuína... As classes sociais e os guetos raciais falam mais sobre os outros que com os outros" (1975, p. 32). Poloneses, húngaros, ingleses, irlandeses, chineses e indianos etc., seguirão mais convencidos do que nunca que seus próprios produtos culturais são superiores aos outros e que eles têm pouco ou nada a aprender.

\section{"Música" como um modo de pensamento e açáo}

Muito se tem escrito sobre a inteligência musical e as capacidades exigidas pelo fazer musical, mas a maior parte é etnocêntrica e nem sempre totalmente apropriada à tradição musical européia da qual são derivados os critérios de mensuração. Em How musical is man? (1973) eu sustentava que a distribuição quase universal da competência musical nas sociedades africanas sugeria que a capacidade musical era, mais que um raro talento, uma característica geral da espécie humana. Também ressaltava 
que bons músicos poderiam evidentemente ganhar muito pouco em testes de musicalidade, porque seus valores e conceitos musicais seriam variados. Por exemplo, as pessoas resistiriam a cantar em uníssono comigo quando solicitadas a fazê-lo, pela razão de que com a presença de mais de uma pessoa qualquer bom músico preferiria cantar em harmonia com intervalos de uma quarta, quinta ou terça! Leon Crickmore (1968) demonstrou que, até mesmo dentro da tradição musical européia, a capacidade para apreciar a música não está correlacionada com a personalidade, medida em qualidade intelectual ou inteligência musical, como calculada pelo teste Wing.

A pesquisa etnomusicológica mostra que grande parte das teorias, parâmetros e testes de musicalidade, assim como das correspondentes psicologias da música, são específicas e culturalmente limitadas, e que a música pode ser gerada por uma variedade de processos, alguns dos quais são "não-musicais" (cf. Blacking, 1973, 11 ff.). Apesar disto, existem boas razōes para procurar e identificar um quadro inato específico das capacidades cognitivas e sensoriais que os seres humanos estão predispostos a usar para a comunicação "musical". Ao postular um modo não-verbal, pré-lingüístico, "musical" de pensamento e ação não quero dizer que todas as músicas são derivadas dele ou que está limitado à produção da música. Além disso, pode manifestar-se em outras atividades humanas, até mesmo na organização de idéias verbais, como ressaltei na primeira seção deste trabalho.

A linguagem verbal surgiu com a nossa atual espécie Homo sapiens sapiens acerca de setenta mil anos e é claramente mais eficiente para a adaptação cultural. Mas a "música" e a "dança" não desapareceram. Tal sobrevivência sugere que este valor evolutivo reside na sua eficácia como linguagem não-verbal, especialmente no uso que faz do hemisfério direito do cérebro, cujo papel na ação humana se tornou menos acentuado que a linguagem verbal desenvolvida, e do hemisfério esquerdo, usado mais freqüentemente em atividades culturais gerais e em certas ocupaçóes (cf. Ornstein, 1973, p. 92). Embora grande parte das ocupaçôes valorize um modo de pensamento ao outro, a "consciência humana completa poderia incluir ambos" e os "trabalhos complementares de nossos dois processos de pensamento nos permitiriam as maiores realizações" (ibid.). Da mesma maneira, embora a comunicação não-verbal seja particularmente apropriada para a expressáo da qualidade e da intensidade dos sentimentos (cf. Bateson, 1973, p. 388), recuso, pois que são de pouca valia, essas dicotomias que opóem os hemisférios direito e esquerdo, música e dança em contraste com linguagem verbal, emoção com razão, e assim por diante.

Os modos de pensar não-verbais, freqüentemente referidos como "performativos/expressivos", são tão fundamentais e necessários para a vida humana como o verbal e outros modos de pensamento "proposicionais/discursivos", característicos do hemisfério esquerdo do cérebro. Além disso, estes dois modos de pensamento, complementares mas contrastantes, não estão atrelados a nenhuma atividade particular, mas são maneiras de processar a informação.

Como um sistema modelar primário, a "música" só pode ser inferida a partir de observaçôes cuidadosas do comportamento e da ação humana. Além do mais, ela provavelmente não pode ser revelada através do estudo intensivo de um sistema em seu contexto social, embora esse método pareça ser produtivo para entender a fala, tendo Chomski e outros realizado grandes progressos no estudo do uso da língua inglesa. Um trabalho como Biological foundations of language (Lenneberg, 1967) não poderia ter sido realizado sobre a "música" com evidências provindas de um único sistema cultural, porque as pessoas não distinguem as músicas umas das 
outras com a mesma certeza que reconhecem outras línguas naturais como fala.

O conceito antropológico de "música" deveria, portanto, ser provisório e sensível à variedade de significados atribuídos, em diferentes partes do mundo, ao som humanamente organizado. Os mesmos padróes de som não apenas podem ter diferentes significados em diversas sociedades, mas também podem ter significados diferentes no interior da mesma sociedade, por causa dos contextos sociais diferentes. Dessa forma, como nos estudos modernos dos atos de fala, a ênfase deve estar nas intençóes de significar algo dos atores e em suas interpretaçôes das intenções de significar das outras pessoas. Isto também obriga a reconhecer que atores e analistas podem interpretar mal as intençôes dos outros, o que pode ter conseqüências para a ação social bem como para o rigor analítico. Isto é, uma pessoa pode interpretar um comportamento não-intencional de outra como uma ação intencional e responder de acordo. Um tique nervoso pode ser interpretado como uma piscadela, ou como um tique nervoso.

A etnomusicologia dialética deve procurar relacionar as variedades de músicas com as características gerais da "música" como um modo de pensamento e ação - por exemplo, relacionar as manifestações culturais aos fundamentos biológicos. Os estudos da natureza da "música" envolvem uma dialética entre cultura e natureza, convençôes ou predisposiçóes sociais e ação individual, plasticidade e especificidade. Mas estes pares contrastantes nem sempre devem ser tratados como oposiçóes ou categorias homólogas. Isto quer dizer, por exemplo, que a plasticidade é uma característica da especificidade humana, embora as variedades das convençôes sociais possam ser descritas como conseqüências desta plasticidade e da ação individual. $\mathrm{O}$ fato de que elas são convenções somente é possível por causa da especificidade humana. Estou interessado em uma série de questóes que o etólogo Robert Hinde considera útil:
A diferença entre este e aquele padrão de comportamento é devida a uma diferença na constituição genética ou na experiência? A diferença na experiência (ou na constituição genética) afeta o padrão de comportamento? [...]

[No caso do tentilhăo,] ouvir um canto normal é parte da experiência necessária para o desenvolvimento deste canto [...] Entretanto, os tentilhôes não aprenderiam nenhum canto ouvido por eles [se] a experiência de aprendê-lo náo ocorresse alguns meses antes do próprio pássaro iniciar a cantar [de modo que a informação], de certa maneira, seja armazenada [...]

Os organismos vêm ao mundo com propensôes para aprender algumas coisas mas não outras [...] os tentilhôes logo terão dificuldades se imitarem qualquer som que ouçam, pois é verdade que está predeterminado que aprendam apenas cantos com a estrutura tonal parecida com aquela do canto normal do tentilhão (Hinde, 1975, p. 114-117).

Não estou interessado no estudo dos sistemas musicais unicamente como exemplos da infinita variedade da criatividade humana, mas no suposto papel da "música" como parte de uma biogramática humana. Se há um fundamento biológico para a "música”, qual é a gama de capacidades envolvidas? E em que medida elas coincidem com outras capacidades? Que outras formas culturais são extensões das mesmas propensões biológicas? $\mathrm{O}$ que acontece às pessoas quando as sociedades não levam em conta ou não estimulam o desenvolvimento das capacidades "musicais" latentes? Elas são canalizadas para outras atividades ou simplesmente atrofiam? Se há fundamentos biológicos das músicas, o quanto eles determinam reaçôes na interpretação das estruturas sonoras?

Há um paradoxo acerca das interpretaçóes privada e pública da música que aponta para a presença e a importância dos fundamentos biológicos. Ele é resumido no tipo de observação 
que Constant Lambert fez ao final de Music Ho!: "O artista membro de um grupo escreve somente para aquele grupo, ao passo que, ao expressar uma experiência pessoal o artista pode, no fim das contas, alcançar uma experiência universal" (1948, p. 241). Isto sugere que a música pode ser uma linguagem universal que transcende cultura, classe, nação e grupo social, mas apenas sob certas condiçóes. Quando ela remete a um conhecimento público, seu apelo é limitado; mas quando é mais privada, pode ter um apelo mais amplo.

A primeira proposição é facilmente aceita. A música não é uma linguagem universal. Como comunicação pública, os sistemas musicais são mais esotéricos e culturalmente específicos do que qualquer linguagem verbal. Eles náo podem ser traduzidos e tornados publicamente acessíveis e inteligíveis para os estrangeiros, assim como se pode falar em línguas estrangeiras em conferências ou reunióes políticas e ser entendido por todos os presentes com o auxílio de bons intérpretes.

A segunda proposição não faz sentido algum, a não ser que postulemos serem alguns aspectos da comunicação não-verbal e da organização cognitiva parte de uma biogramática humana (cf. Blacking, 1977, 10ff.). Pela experiência sabemos que não podemos produzir qualquer sentido da fala de outra pessoa sem utilizar um intérprete ou gastar tempo e esforço consideráveis apreendendo sua gramática e seu léxico. Mas também sabemos que podemos privadamente produzir sentido da música de, digamos, Schubert, Mozart e alguns compositores balineses sem qualquer conhecimento ou mesmo tendo pouco interesse nas culturas e línguas austríaca e balinesa. Como é possível?

Mesmo que seja necessário algum treinamento musical ou endoculturação em pelo menos um sistema musical, o ponto é que podemos produzir sentido dos sistemas musicais sem ter que perder tempo aprendendo seus códigos, como temos que produzir sentido da fala estrangeira. Isto sugere que haveria uma ressonância cognitiva supracultural e níveis nos quais diferentes compositores, ouvintes e sistemas musicais utilizam os mesmos modos "musicais" de pensamento. Contudo, a experiência de tal ressonância somente pode ser privada, porque os sentimentos públicos inclinam as pessoas para aquilo que é culturalmente familiar. Além disso, a afirmação de que a música é uma "linguagem de emoçóes, parecida com a fala" (Cooke, 1959), que revela "a natureza dos sentimentos com um detalhe e uma verdade que a língua não pode abordar" (Langer, 1948, p. 191), não poderia explicar a comunicação musical "universal". Não apenas as convençôes artísticas e a expressão emocional muda de uma cultura para outra, como também as maneiras pelas quais as pessoas aprendem a classificar, a usar suas emoções e a desenvolver uma vida de sentimentos varia consideravelmente.

O tipo de comunicação musical que Costant Lambert (1948) descreveu e a experiência de centenas de milhares de pessoas podem não ocorrer regularmente, a não ser que os indivíduos possuíssem alguma espécie de inteligência "musical" cujo uso não depende completamente da experiência e do condicionamento cultural.

Como um meio de comunicação, a música difere da fala e do mito, pois o significado (mensagem) é geralmente fixado independentemente da estrutura (código). Embora qualquer significado extra-musical (por exemplo, social, político ou religioso) possa ser fixado para o conjunto dos símbolos musicais, a explicação torna-se um problema sociológico, e o significado musical depende muito da estrutura do som. A fala agramatical pode ser compreendida, mas a música sem estrutura é ininteligível ou, de qualquer forma, ineficaz como comunicação musical. (A música aleatória não é uma exceção, porque é geralmente incorporada em estruturas musicais. Isto 
não pode ser comparado precisamente com a glossolalia, que não é tratada como fala agramatical.)

Como estrutura, a música é sobretudo sensual e não-referencial: ela proporciona "uma representação de fatos conhecidos, característica não da experiência objetiva em si, mas de nossa consciência da experiência objetiva" (Ferguson, 1960 , p. 88). Ela não pode comunicar nada novo a não ser padróes desconhecidos de som e, num certo sentido, não exprime nada mais que ela mesma: provoca emoçóes apenas com base na compreensão dos contrastes tonais e rítmicos (cf. Meyer, 1956; Pike, 1970; Clynes, 1974). No entanto, essas estruturas são criadas e fixam significado na cultura (cf. Blacking, 1973, p. 54-58), e assim a música exprime tudo menos ela mesma, da mesma maneira que a fala exprime tudo menos a fonologia e a sintaxe para quem usa uma língua especificamente. Portanto, até as explicaçóes fenomenológicas do significado musical intrínseco não podem evitar o fato de que os símbolos e os sistemas musicais são socialmente construídos, e de que a comunicação musical se torna possível não pelas estruturas musicais per se, mas pelo sentido musical que as pessoas encontram nela.

Se "ao expressar uma experiência pessoal o artista pode, no fim das contas, alcançar uma experiência universal", é porque ele ou ela é capaz de viver além da cultura - e não para a cultura (cf. Blacking, 1969, p. 16) - e de ressintonizar as convençôes culturais particulares com as experiências comuns dos seres humanos pelo uso dos modos de pensamento que todo indivíduo possui. Quando a gramática da música coincide com a gramática do corpo de uma pessoa particular, a ressonância cognitiva pode, em parte, ser sentida e apreendida por causa da experiência social. Mas quando a gramática da música coincide com a biogramática "musical" do corpo humano, em sentido amplo, a ressonância cognitiva pode ser sentida e apreendida apesar das experiências sociais específicas. Uma compreensão intuitiva da música é possível porque performers e ouvintes possuem, tal como criadores de música, a mesma "competência" ou "inteligência" musical inata. Quando alguém usa esses modos de pensamento e açáo muito pessoais (mas "universais") para criar novas combinaçóes com os símbolos musicais culturalmente familiares, há uma boa chance de outros seres humanos, recriando suas percepçôes ao ouvi-las (é sobre isso que trata a audição ativa), sentirem em seus corpos o que os outros sentiram ao criá-las. E desde que estes sentimentos sejam parte essencial das atividades do corpo humano, eles serão acompanhados pelas experiências de plenitude, de satisfação e de bem sucedida auto-atualização.

Tudo isso é uma elaboração a partir da frase de Geertz, citada anteriormente, de que a "arte e o equipamento para sua compreensão são produzidos na mesma oficina”. Mas gostaria de reiterar dois pontos. Primeiro, o processo de ressonância em nada depende do condicionamento cultural, podendo ser um fenômeno da comunicação humana não-verbal. Em segundo lugar, os sentimentos primários que as pessoas têm em seus corpos são experiências de diferentes tipos de impulso interno. Mais que sensaçóes de emoçóes particulares ou estados físicos, elas podem escolher interpretar tais sentimentos com linguagens contemporâneas da emoção e outras metáforas culturalmente familiares. Entretanto, não chegaremos a uma teoria coerente da comunicação musical se tentarmos explicar diferentes sistemas musicais como linguagens de emoções: como uma capacidade humana, a "música" é uma atividade cognitiva e, portanto, afetiva do corpo.

As análises críticas das estruturas musicais e de seus significados para atores e analistas, em diferentes contextos sociais e históricos, podem complementar experimentos formais e levarnos mais próximo à compreensão da "música" 
como uma capacidade humana. Aquilo que denomino "dança biossocial" (Blacking, 1976) é uma capacidade específica, o instrumental que permitiu ao homem primitivo desenvolver o pensamento, a tecnologia e a invenção da cultura na época do baixo Pleistoceno. Sugeri que a "proto-música" e a "proto-dança" estiveram intimamente vinculadas à expansão dessa capacidade e que, como açáo ritualizada no espaço e no tempo, provavelmente foram cruciais ao ajudar as espécies humanas mais primitivas do Homo erectus a desenvolverem-se em Homo sapiens neanderthalensis e daí em Homo sapiens sapiens.

Com o advento do Homo sapiens sapiens veio a linguagem verbal, mas não o desaparecimento da "música" e da "dança". Os símbolos da fala possibilitaram uma grande diversidade de invençáo cultural, em um grau de desenvolvimento até agora sem precedentes. Mas a fala também permitiu aos seres humanos imaginar, desenvolver e debater sobre situaçôes sem necessariamente conhecê-las pela experiência corporal. Há muito os padrôes da música e da dança são influenciados pela forma e pelo conteúdo do discurso verbal, e provavelmente perderam sua importância como modo diário de comunicação factual ou prática. Mas não há razão para supor que seu papel evolutivo tenha diminuído. Lembro que a música e a dança permaneceram como fatores-chave na vida humana e, em particular, são meios para as pessoas preencherem os vazios da comunicação e da compreensão entre suas vidas em sociedades - que prescrevem certas idéias, sentimentos e definições de experiência - e suas experiências corporais como seres com sentimentos próprios.

Se nós soubéssemos mais sobre a "música" como uma capacidade humana, e sobre seu potencial como força intelectual e afetiva na comunicação, na sociedade e na cultura, poderíamos usá-la amplamente para melhorar a educação geral e construir sociedades pacíficas, igualitárias e prósperas no século XXI, assim como nossos ancestrais pré-históricos usaramna para inventar as culturas a partir das quais todas as civilizaçôes se desenvolveram.

\section{Referências bibliográficas}

AROM, Simha. The use of play-back: techniques in the study of oral polyphonies. Ethnomusicology, n. 20, p. 483-519, 1976.

BARKÓCZI, Ilona; PLÉH, Czaba. Music makes a difference. Budapest: [s.n.], 1982. [s.i.]

BATESON, Gregory. Steps to an ecology of mind. St. Albans: Paladin, 1973.565 p.

BAXANDALL, Michael. Painting and experience in fifteenth-century Italy. Oxford: Clarendon Press, 1972. 192 p.

BLACKING, John. Problems of pitch, pattern and harmony in the ocarina music of the Venda. African $M u-$ sic, vol. 2, n. 4, p. 15-23, 1959.

Venda children's songs: a study in ethnomusicological analysis. Johanesburg: Witwatersrand University Press, 1967. 210 p.

Process and products in human society (Inaugural lecture). Johannesburg: Witwatersrand University Press, 1969. 23 p.

How musical is man? Seattle: University of Washington Press, 1973. 116 p.

Dance, conceptual thought and production in the archaeological record. In: SIEVEKING, G. de G.; LONGWORTH, I. H.; WILSON, K. E. (Eds.). Problems in economic and social archaeology. London: Duckworth, 1976. p. 3-13.

Towards an anthropology of the body. The Anthropology of the Body (ASA Monographs 15). London: Academic Press, 1977. p. 1 -28.

The problem of "ethnic" perceptions in the semiotics of music. In: STEINER, W. (Ed.). The sign in music and literature. Austin: University of Texas Press, 1981. p. 184-194.

A case for higher education in the arts. In: ROBINSON, K. (Ed.). The arts and higher education (Research into Higher Education Monographs 48). Guildford: Society for Research into Higher Education, University of Surrey, 1982. p. 26-50.

What languages do musical grammars describe? In: BARONI, M.; CALLEGARI, L. (Eds.), Musical 
grammars and computer analysis. Florence: Leo S. Olschki, 1984. p. 363-370.

Chapter 1: Expressing music experience through music. Music, culture \& experience - selected papers of John Blacking; edited and with an introduction by Reginald Byron; with a foreword by Bruno Nettl. Chicago and London: University of Chicago Press, 1995a. p. 31- 72.

Chapter 7: The music of politics. Music, Culture \& Experience - selected papers of John Blacking; edited and with an introduction by Reginald Byron; with a foreword by Bruno Nettl. Chicago and London: University of Chicago Press, 1995b. p. 198 - 222.

CLYNES, Manfred. The pure pulse of musical genius. Psychology today, July, p. 51-55, 1974.

COOKE, Derryck. The language of music. London: Oxford University Press, 1959. 304 p.

CRICKMORE, Leon. An approach to the measurement of music appreciation. Journal of Research in Music Education, n. 26, p. 239-253/291-301, 1968.

ELLIS, Alexander John. On the musical scales of the various nations. Journal of the Society of Arts, n. 38, p. 485-527, 1885.

FELD, Steve. Sound and sentiment: birds, weeping, poetics, and song in Kaluli expression. Philadelphia: University of Pennsylvania Press, 1982.316 p.

FERGUSON, Donald. Music as metaphor. Minneapolis: University of Minnesota Press, 1960. 198 p.

GARDNER, Howard. The arts and human development. New York: Wiley, 1973. 428 p.

GEERTZ, Clifford. The interpretation of cultures. London: Hutchinson, 1975. 470 p.

Art as a cultural system. Modern language notes, n. 91, p. 1473-1499, 1976.

HINDE, Robert. The comparative study of nonverbal communication. In: BENTHALL, J.; POLHEMUS, T. (Eds.). The body as a medium of expression. London: Allen Lane, 1975. p. $107-142$

HORNBOSTEL, Erich Moritz von. The unity of the senses. Psyche, n. 7, p. 85-89, 1927.

LAMBERT, Constant. Music Ho!: a study of music in decline. 3rd edition. Harmondsworth: Penguin, 1948. $304 \mathrm{p}$.

LANGER, Susanne. Philosophy in a new key. New York: Mentor Books, 1948. 248 p.

LEACH, Edmond. Political systems of Highland Burma. London: G. Bell for the London School of Economics and Political Science, 1954. [s.i.]

LENNEBERG, Eric. Biological foundations of language. New York: Wiley, 1967.528 p.
MESSNER, Gerald. Die Schwebungsdiaphonie in Bistrica. Tutzing: Hans Schneider, 1980. [s.i.]

MEYER, Leonard. Emotion and meaning in music. Chicago: University of Chicago Press, 1956. 315p.

NZEWI, Meki. Master musicians and the music of UKOM, ESE, and MGBA ensembles in in Ngwa, Igbo society. Ph.D. dissertation, The Queen's University, Belfast, 1977. [s.i.]

ORNSTEIN, Robert. Right and left thinking. Psychology today, May, p. 87-92, 1973.

PETROVIC, Ankica. Ganga: A Form of tradicional rural singing in Yugoslavia. Ph.D. dissertation, The Queen's University, Belfast, 1977. [s.i.]

PIKE, Alfred. A phenomenological analysis of musical experience and other related essays. New York: St. John's Press, 1970. 75 p.

SCHNEIDER, Louis; BONJEAN, Charles. The idea of culture in the social sciences. Cambridge: Cambridge University Press, 1973. 158 p.

SEEGER, Charles. Speech, music, and speech about music. In: SEEGER, S. (Ed.) Studies in musicology $1935-$ 1975. Berkeley: University of California Press, 1977. p. $16-35$.

SIDRAN, Ben. Black talk. New York: Holt, Rinehart and Winston, 1971. $201 \mathrm{p}$.

STEINER, George. After Babel: aspects of language and translation. London: Oxford University Press, 1975. $507 \mathrm{p}$.

TAX, Meredith. Culture is not neutral: whom does it serve? In: BAXANDALL, L. (Ed.). Radical perspectives in the arts. Harmondsworth: Penguin, 1972. p. 15 -29.

TYLOR, Edward Burnett. Primitive culture. London: John Murray, 1871.[s.i.]

\section{Agradecimentos}

Em primeiro lugar, devo agradecer à Christine Lucia e Dr. Stephanus Muller, respectivamente editora da South African Journal of Musicology (SAMUS) e presidente da Musicological Society of Southern Africa, por autorizarem a publicação desta versão em português. Agradeço aos colegas Danilo Paiva Ramos, Herbert Rodrigues e Giovanni Cirino pela colaboração na tradução, bem como aos três editores da $\mathrm{Ca}$ dernos de Campo responsáveis pela apreciação desta e por suas generosas sugestóes ao texto. 
2I 8 | JOHN BLACKING

traduzido de

BLACKING, John. Music, culture, and experience. In: Music, culture \& experience - selected papers of John Blacking; edited and with an introduction by Reginald Byron; with a foreword by Bruno Nettl. Chicago and London: University of Chicago Press, 1995. p. 223-242.

\author{
tradutor André-Kees de Moraes Schouten \\ Doutorando em Ciência Social (Antropologia Social)/USP \\ Pesquisador do Núcleo de Antropologia da Performance e do Drama (NAPEDRA/USP) \\ revisor Daniela do Amaral Alfonsi \\ Mestre em Ciência Social (Antropologia Social)/USP \\ tradutor Paula Wolthers de Lorena Pires \\ Mestranda em Ciência Social (Antropologia Social)/USP \\ tradutor Thaís Chang Waldman \\ Mestranda em Ciência Social (Antropologia Social)/USP
}

Recebido em 19/03/2007

Aceito para publicação em 16/07/2007 